\title{
Production and Characterization of Surface-active Compounds from Gordonia amicalis
}

\author{
Ani Beatriz Jackisch-Matsuura ${ }^{1^{*}}$, Leonardo Silva Santos ${ }^{2}$, Marcos Nogueira Eberlin ${ }^{3}$, Andréia Fonseca de \\ Faria $^{6}$, Takeshi Matsuura ${ }^{4}$, Matthew James Grossman ${ }^{5}$ and Lucia Regina Durrant ${ }^{6}$ \\ ${ }^{l}$ Centro de Pesquisa Leônidas e Maria Deane/Fiocruz Amazônia, Manaus - AM - Brasil. ${ }^{2}$ Instituto de Química de \\ Recursos Naturales; Universidad de Talca; Talca - Chile. ${ }^{3}$ Laboratório Thomson de Espectrometria de Massas; \\ Instituto de Química; Universidade Estadual de Campinas; Campinas - SP - Brasil. ${ }^{4}$ Instituto de Ciências \\ Biológicas; Universidade Federal do Amazonas; Manaus - AM - Brasil. ${ }^{5}$ BioSage; Lawrenceville, New Jersey - \\ USA. ${ }^{6}$ Faculdade de Ciências de Alimentos; Universidade Estadual de Campinas Campinas - SP - Brasil
}

\begin{abstract}
Two methods were used to make crude preparations of surface-active compounds (SACs) produced by Gordonia amicalis grown on the medium containing 1\% diesel oil. Using a 2:1 (v/v) solution of chloroform:methanol for extraction, Type I SACs were isolated and shown to produce oil in water (O/W) emulsions. Type II SACs were isolated by precipitation with ammonium sulfate and produced predominantly water in oil emulsions $(W / O)$. The crude Type I and II preparations were able to produce a significant reduction in the surface tension of water; however, the crude Type II preparation had 10-25 fold higher emulsification activity than the Type I preparation. Both SAC preparations were analyzed by the TLC and each produced two distinct bands with $R_{f} 0.44$ and 0.62 and $R_{f} 0.52$ and 0.62 , respectively. The partially purified SACs were characterized by the ESI(+)-MS, FT-IR and NMR. In each one of these fractions, a mixture of 10 oligomers was found consisting of a series of compounds, with masses from 502 to 899, differing in molecular mass by a repeating unit of 44 Daltons. The mass spectra of these compounds did not appear to match other known biosurfactants and could represent a novel class of these compounds.
\end{abstract}

Key words: Bioemulsifier, bioremediation, biosurfactant, Gordonia amicalis, industrial chemicals, microbial surfactant production

\section{INTRODUCTION}

Gordonia strains have received considerable attention recently due to their ability to degrade a wide variety of xenobiotic and environmental pollutants such as alkanes, polyisoprenes and aromatic hydrocarbons as well as for their ability to desulfurize dibenzothiophene and benzothiophene. The production of surface-active compounds (SACs) by Gordonia sp. has been associated with their ability to degrade the hydrophobic compounds (Arenskötter et al. 2004). However, very little information is currently available about the SACs produced by the Gordonia members. In biomedicine, biosurfactants, or their derivatives are used as detergents, disinfectants, biocides, anti-adhesive coatings, and anti-thrombotic agents. In the food industry, they are used as emulsifiers for the processing of raw materials whereas in agriculture, biosurfactants are used for biological control of plant pathogens. These versatile molecules are also of interest in the cosmetic industry because of their

*Author for correspondence: ani@amazonia.fiocruz.br 
moisturizing properties and skin compatibility (Brown 1991; Stanghellini and Miller 1997; Banat et al. 2000; Singh et al. 2007).

This work aimed to study the production and isolation of two different preparations of SAC's using a Gordonia amicalis strain isolated from diesel-contaminated soil and the partial characterization of the structures of the compounds.

\section{MATERIALS AND METHODS}

\section{6s Sequence Analysis of the Biosurfactant Producing Isolate}

G. amicalis strain DRM 190-07 was isolated from the soil contaminated with diesel oil collected near the REPLAN petroleum refinery in Campinas, São Paulo, Brazil. This strain was originally identified by morphological and biochemical analysis as Planococcus citreus strain CCT 4018 (Jacobucci et al. 2001; Jacobucci et al. 2009). The isolate has been subsequently reclassified as G. amicalis based on $16 \mathrm{~S}$ rDNA sequence analysis. Total DNA from an isolated colony was purified with the Qiagen genomic DNA extraction kit (Qiagen, CA, USA) according to the manufacturer's instructions. Primers for amplification of $16 \mathrm{~S}$ rDNA were $\mathrm{p} 27 \mathrm{~F}$ (5'-AGA GTT TGA TCM TGG CTC AG-3' ('M = A or C)) and p 1401R (5'-GCG TGT GTA CAA GAC CC-3'), homologous to the conservative ends of bacterial $16 \mathrm{~S}$ rDNA. Amplicons obtained from the 16S rDNA were purified (GFX PCR DNA and Gel Band Purification kit GE Health Care, USA) and sequenced with a MegaBACE automated sequencing system (1000 GE Health Care, USA). The sequence (1293 bp) was compared to the Ribosomal Database Project (RDP) data base and a phylogenetic tree was produced using a range of Gordonia 16S sequences obtained from the GeneBank database using the RDP online tools "Seqmatch" and "Tree Builder" (Cole et al. 2007; Cole et al. 2009). Comparison of the sequence against the GeneBank database revealed that it was $100 \%$ identical to that of a $G$. amicalis isolated previously and identified as a dibenzothiophenedesulphurizing actinomycete (11, 16S Genebank sequence ID AF101418.1, RDP identifier S000428902). Figure 1 show a phylogenetic tree based on alignment of the $16 \mathrm{~S}$ sequence of the surfactant producing isolate and other Gordonia sequences obtained from the RDP (http://rdp.cme.msu.edu/) database.

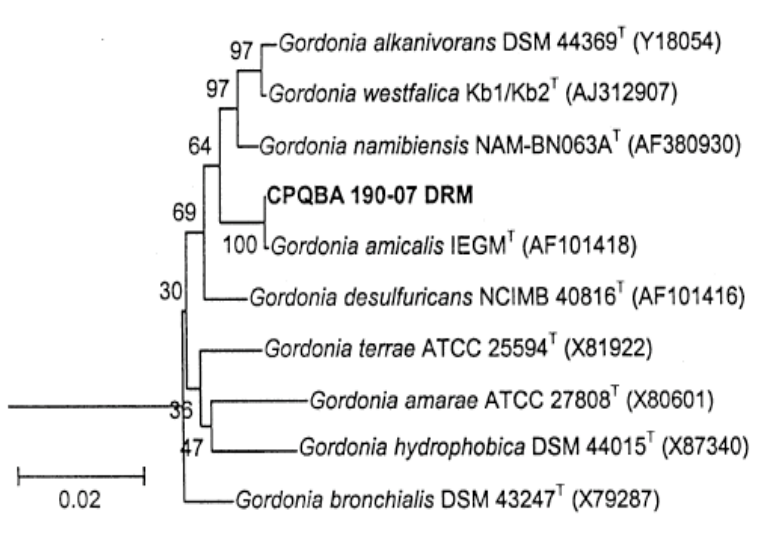

Figure 1 - Phylogenetic tree of the 16S sequence Gordonia amicalis surfactant producing isolate (indicated as CPQBA 190-07 DRM) and $16 \mathrm{~S}$ sequences from a variety of other Gordonia species. Numbers on the tree are bootstrap values. Distance is indicated by the scale bar.

\section{Biosurfactant Production and Isolation}

The bacterium was grown on GYP medium (2\% glucose, $0.5 \%$ yeast extract; $1 \%$ peptone; $2 \%$ agar) at $30^{\circ} \mathrm{C}$ for $72 \mathrm{~h}$, after which the cells were harvested and cell suspensions with $\mathrm{OD}_{610 \mathrm{~nm}}=2.0$ were prepared and used to inoculate $7 \mathrm{~L}$ of liquid medium $(1 \mathrm{~mL} / 50 \mathrm{~mL}$ medium) in a BioFlo III fermenter (New Brunswick Scientific) with $14 \mathrm{~L}$ capacity. The medium contained (\%) $0.05 \mathrm{MgSO}_{4}$, $0.3 \mathrm{NaNO}_{3}, 0.1 \mathrm{KH}_{2} \mathrm{PO}_{4}, 0.1$ yeast extract and 0.03 peptone, and supplemented with $1 \%$ diesel oil. The inoculated medium was incubated at $30^{\circ} \mathrm{C}$ with $250 \mathrm{rpm}$ agitation and $0.3 \mathrm{vvm}$ aeration for 72 h (Rapp and Backhaus 1992). Culture broth was made cell free by centrifugation at 16,192 xg for 15 minutes, followed by filtration through a Whatman 1 filter. Crude extracts of Type I SACs were obtained by extraction with chloroform/methanol (2:1, v/v) (Rocha et al. 1992) while Type II SACs were obtained by precipitation with ammonium sulfate (Navon-Venezia et al. 1995). Crude extracts of both Type I and II SACs were lyophilized and maintained at $4{ }^{\circ} \mathrm{C}$ until used.

\section{Surface Tension Measurement}

The surface tension of the culture broth $(20 \mathrm{~mL})$, raw extracts of Type I ( 1 to $5 \mathrm{mg} / \mathrm{mL}$ ) and Type II $(0.2 \mathrm{mg} / \mathrm{mL})$ and partially purified Type I SACs $(1.5 \mathrm{mg} / \mathrm{mL})$ were evaluated. Lyophilized crude extracts and partially purified SACs were redissolved in deionized water and the surface tension of these preparations and the culture broth was measured with a tensiometer (K10ST; Krüss, 
Hamburg, Germany) at $20^{\circ} \mathrm{C}$ by the $\mathrm{Du}$ Nouy method using a platinum-iridium ring.

\section{Emulsification Test}

Emulsification was evaluated using SAC preparation solutions as described for surface tension measurements in $1.0 \mathrm{~cm}$ diameter test tubes containing $3.5 \mathrm{~mL}$ of the Type I, or Type II solutions and $2.0 \mathrm{~mL}$ of toluene as emulsification substrate. Optical density was measured at $610 \mathrm{~nm}$ with a spectrophotometer before and after vigorous mixing for one minute on a vortex mixer. The $\Delta \mathrm{OD}$ was reported as oil-in-water $(\mathrm{O} / \mathrm{W})$ emulsification activity. After $24 \mathrm{~h}$, the height of the emulsion layer that formed above the aqueous phase was measured and reported as water-in-oil (W/O) emulsification activity and expressed in $\mathrm{cm}$. Water-in-oil emulsification activities were classified based on the emulsion height formed as high $(\geq 1.8 \mathrm{~cm})$, moderate $(1$ to $1.7 \mathrm{~cm})$ and low $(<1 \mathrm{~cm})$. Oil-in-water emulsions were classified as high $\mathrm{OD}_{610 \mathrm{~nm}} \geq 1.2$, moderate $\mathrm{OD}_{610 \mathrm{~nm}} 0.7$ to 1.1 and low $\mathrm{OD}_{610 \mathrm{~nm}} 0.1$ to 0.6 .

\section{Comparison of G. amicalis's Sacs with Commercial Surfactants}

Surface tension measurements and emulsification activities of the SACs isolated from G. amicalis's growth media were compared to those obtained with the synthetic surfactants such as Triton $\quad \mathrm{X}-100^{\circledR}$ (t-octylphenoxypolyethoxyethanol), $\quad$ Niaproof $^{\circledR}$ (Sodium 7-ethyl-2methyl-4-undecyl sulfate) and Span $20^{\circledR}$ (Sorbitan monolaurate), and the biosurfactant Surfactin (all obtained from Sigma) and used at the concentration of $106 \mu \mathrm{g} / \mathrm{mL}, 415 \mu \mathrm{g} / \mathrm{mL}$ and 516 $\mu \mathrm{g} / \mathrm{mL}$, and $200 \mu \mathrm{g} / \mathrm{mL}$, respectively.

\section{Antimicrobial activity}

Type I and II extracts were assayed for antimicrobial activity by the diffusion method in agar at concentrations of 10, 100, 1000 and 10000 $\mathrm{mg} / \mathrm{L}$. Ten $\mu \mathrm{L}$ of each SAC solution were added to a $6.0 \mathrm{~mm}$ paper filter disk and tested against Staphylococcus aureus, Bacillus cereus, Pseudomonas aeruginosa, Escherichia coli, Listeria monocytogenes, Mycobacterium smegmatis, Candida albicans and Aspergillus flavus.

\section{Thin-Layer Chromatography}

Thin-layer chromatography (TLC) was carried out on silica gel 60 F 254 plates (Merck). Crude extracts $(2.5 \mathrm{mg})$ of the SACs were dissolved in $100 \mu \mathrm{L}$ of methanol. Ten microliter aliquots of the methanol solutions were developed with chloroform/MeOH/ $/ \mathrm{NH}_{4} \mathrm{OH}$ (65:25:4). After airdrying, the SACs were identified by spraying the plates with Rhodamine 6G $(0.005 \%)$ and visualizing under $\mathrm{UV}$ light and by UV visualization alone. After TLC treatment, the partially purified SAC's were obtained by scraping the bands off the plates and re-suspended in the TLC eluting phase solution. The solubilized SAC's were transferred to a fresh tube to remove silica gel and evaporated under reduced pressure to remove the solvent. The partially purified SACs were used for subsequent analysis.

\section{Electrospray Ionization Mass Spectrometry (ESI(+)-} MS), FT-IR AND NMR

The fractions of the crude extracts separated by thin layer chromatography were identified and characterized by ESI(+)-MS, FT-IR and NMR. ESI(+)-MS analysis used a high-resolution Q-TOF mass spectrometer (Micromass, UK). Fourier Transform Infrared spectroscopy (FT-IR) was performed in a Nicolet Impact 410 using $\mathrm{NaCl}$, or $\mathrm{KBr}$ cell films. The absorbance bands were expressed in $\mathrm{cm}^{-1}$. Nuclear Magnetic Resonance analyses were performed in a Varian Gemini-2000 (300 MHz, 7.9 Tesla) equipment and chemical shifts were expressed in $(\delta) \mathrm{ppm}$ values using tetramethylsilane (TMS) as the internal standard for ${ }^{1} \mathrm{H}$ NMR.

\section{RESULTS AND DISCUSSION}

The surface tension of the G. amicalis cell-free culture broth was reduced to $37 \mathrm{mN} / \mathrm{m}$ after $72 \mathrm{~h}$ of cultivation and formed $\mathrm{O} / \mathrm{W}$ emulsions. For comparison, water was used, which had a surface tension of $72 \mathrm{mN} / \mathrm{m}$ at $25^{\circ} \mathrm{C}$. Crude Type I SACs (isolated by chloroform-methanol extraction) were obtained with a yield of $0.53 \mathrm{~g} / \mathrm{L}$. As is shown in Table 1, $5.0 \mathrm{mg} / \mathrm{mL}$ of the crude Type I preparation reduced the surface tension of water to $37 \mathrm{mN} / \mathrm{m}$ and had high oil in water $(\mathrm{O} / \mathrm{W})$ emulsion activity $\left(\mathrm{OD}_{610 \mathrm{~mm}}=2\right)$. Crude extracts of Type II SACs (isolated by ammonium sulfate precipitation) were isolated with a yield of 0.11 $\mathrm{g} / \mathrm{L}$. At a concentration of $0.2 \mathrm{mg} / \mathrm{mL}$ the Type II crude extract demonstrated excellent water in oil (W/O) emulsification activity, with an emulsion phase of $2.3 \mathrm{~cm}$ height after $24 \mathrm{~h}$. However, there 
was no significant production of an $\mathrm{O} / \mathrm{W}$ emulsion. The surface tension of water was reduced to $55.6 \mathrm{mN} / \mathrm{m}$ by the Type II preparation at $0.2 \mathrm{mg} / \mathrm{L}$ (Table 1).

Table 1 - Emulsification activity and surface tension of solutions of commercially available surfactants and Gordonia amicalis's SACs tested in different concentrations.

\begin{tabular}{lccc}
\hline SACs & $\begin{array}{c}\text { Emulsion } \\
\text { O/W } \\
\left(\mathbf{O D}_{610 n m}\right)\end{array}$ & $\begin{array}{c}\text { Emulsion } \\
\text { W/O }(\mathbf{c m})\end{array}$ & $\begin{array}{c}\text { ST } \\
(\mathbf{m N} / \mathbf{m})\end{array}$ \\
\hline $\begin{array}{l}\text { Crude Extract Type I } \\
(5000 \mu \mathrm{g} / \mathrm{mL})\end{array}$ & $>2.0$ & - & 37 \\
$\begin{array}{l}\text { Crude Extract Type I } \\
(1000 \mu \mathrm{g} / \mathrm{mL})\end{array}$ & 1.3 & & 42.9 \\
$\begin{array}{l}\text { Crude Extract Type II } \\
(200 \mu \mathrm{g} / \mathrm{mL})\end{array}$ & - & 2.3 & 55.6 \\
Surfactin $(200 \mu \mathrm{g} / \mathrm{mL})$ & - & 2.1 & 32.6 \\
Triton X-100 & - & 2.2 & 31 \\
$(106 \mu \mathrm{g} / \mathrm{mL})$ & - & & \\
Span 20 $(516 \mu \mathrm{g} / \mathrm{mL})$ & - & 1.0 & 29.3 \\
Niaproof $(415 \mu \mathrm{g} / \mathrm{mL})$ & - & 2.2 & 53.8 \\
\hline
\end{tabular}

Triton X-100, Span 20, Niaproof and Surfactin showed similar W/O emulsification abilities as the Type II extract, totally emulsifying all the oil substrate, with the exception of Span 20, which emulsified only $50 \%$ of the substrate at a concentration of $516 \mu \mathrm{g} / \mathrm{mL}$. However, it lowered the surface tension of water to $29.3 \mathrm{mN} / \mathrm{m}$. None of the commercial surfactants produced significant $\mathrm{O} / \mathrm{W}$ emulsification activity at the concentrations used here.

Two distinct spots were detected by the TLC from the Type I and II crude extracts. Extract Type I produced spots with $\mathrm{R}_{\mathrm{f}} 0.44$ and 0.62 ; Type II produced spots with $\mathrm{R}_{\mathrm{f}} 0.52$ and 0.62 . The SACs recovered from the Type I band with $R_{f} 0.62$ were tested for their ability to reduce the surface tension of water and a decrease to $35 \mathrm{mN} / \mathrm{m}$ was observed at a concentration of $1.5 \mathrm{mg} / \mathrm{mL}$. In contrast, the Type I SACs from the TLC band with $\mathrm{R}_{\mathrm{f}} 0.44$ were less effective than those from band $R_{f} 0.62$ at reducing the surface tension of water. Both the $R_{f}$ 0.44 and 0.62 SAC's produced $\mathrm{O} / \mathrm{W}$ emulsions; however those from $R_{f} 0.44$ were more effective.

The partially purified SAC from the Type $\mathrm{I} \mathrm{R}_{\mathrm{f}} 0.62$ band was further characterized by ESI(+)-MS and FT-IR and ${ }^{1} \mathrm{H}$ NMR spectroscopy. In the ESI(+)MS of the Type $I_{\mathrm{f}} 0.62$ band, a homologue series of 10 ions separated by $44 \mathrm{~m} / z$ units dominated from $m / z 502$ to $m / z 899$ (Fig. 2).

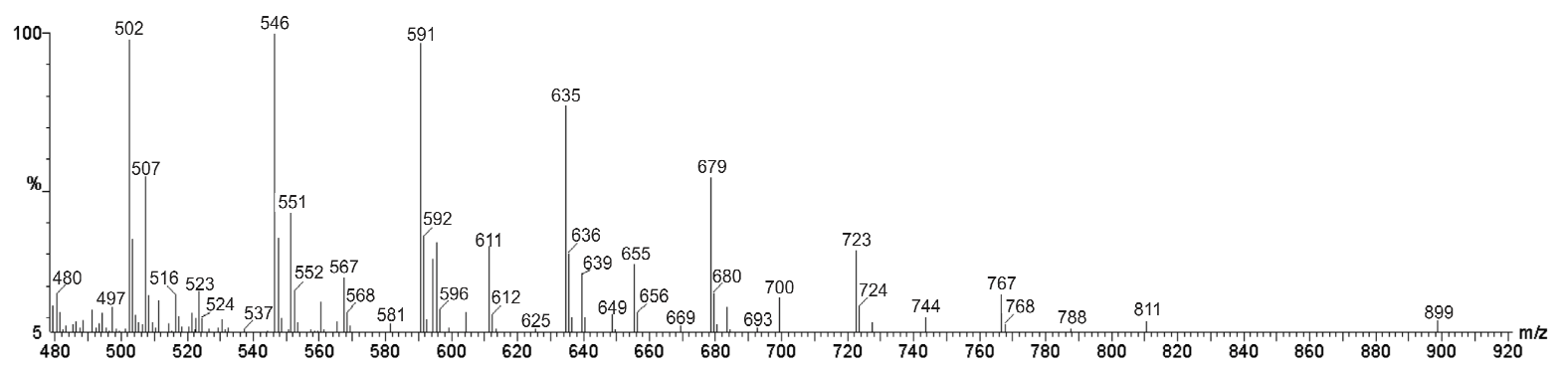

Figure 2 - ESI(+)-MS spectrum for the sample of $R_{f} 0.62$ from the extract Type I produced by Gordonia amicalis.

The results suggested that these were oligomers containing a repeating unit of $44 \mathrm{Da}$. The ${ }^{13} \mathrm{C}$ isotopologue ions with its $\mathrm{m} / \mathrm{z}$ value 1 unit higher $(\mathrm{m} / z 591$ and 592 for instance) showed that these species were singly charged protonated molecules, that is $[\mathrm{M}+\mathrm{H}]^{+}$ions. To our knowledge a biosurfactant with a similar ESI(+)-MS subunit pattern for which $-\left(\mathrm{CH}_{2} \mathrm{CH}_{2} \mathrm{O}\right)_{\mathrm{n}^{-}}$or an isomeric unit such as $-\left(\mathrm{CH}_{2} \mathrm{CH}(\mathrm{OH})\right)_{\mathrm{n}}$ - seems likely and has not previously been reported (Nitschke et al. 2004; Nitschke et al. 2005; Jacques et al. 2007; de Araújo et al. 2011).

FT-IR analysis of the Type I SACs from the $\mathrm{R}_{\mathrm{f}}$
0.62 band (Fig. 3) showed a fairly broad band at $3403 \mathrm{~cm}^{-1}$, suggesting a $\mathrm{OH}$ functional group from an alcohol, not to a carboxylic acid, which have been typically broader and centered around 3000 $\mathrm{cm}^{-1}$. The bands at 1022 and $1092 \mathrm{~cm}^{-1}$ were consistent with the $\mathrm{C}-\mathrm{O}$ stretch bands observed for the alcohols. The sharp bands at 2961, 2919 and $2850 \mathrm{~cm}^{-1}$ were indicative of the presence of $\mathrm{C}-\mathrm{H}$ bands. No C-C aromatic bands (1530-1560 $\left.\mathrm{cm}^{-1}\right)$ were detected. The bands at 1709 and $1639 \mathrm{~cm}^{-1}$ suggested the presence of $\mathrm{C}=\mathrm{O}$ carbonyl bond and the band in $1639 \mathrm{~cm}^{-1}$ was consistent with the $\mathrm{C}=\mathrm{O}$ stretch band of an amide. 


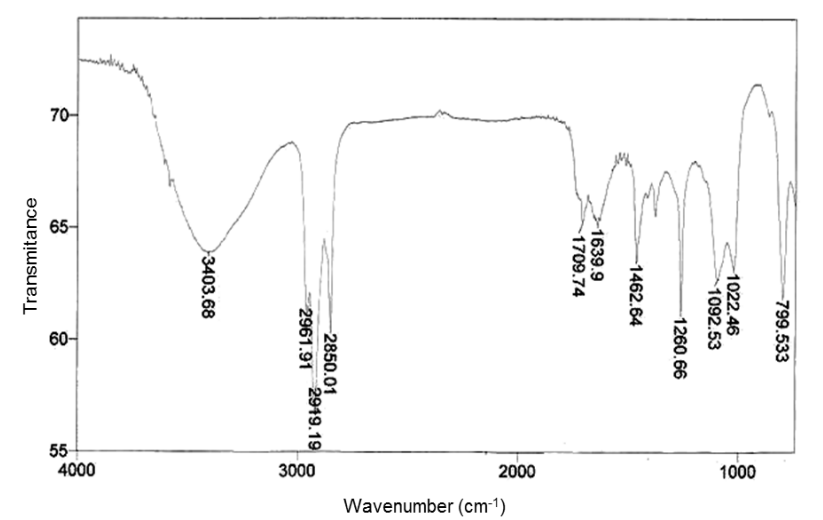

Figure 3 - FT-IR spectrum for the sample of $\mathrm{R}_{\mathrm{f}} 0.62$ from the extract Type I produced by $G$. amicalis.

${ }^{1} \mathrm{H}$ NMR $\left(300 \mathrm{MHz}, \mathrm{CDCl}_{3}\right)$ analysis of the Type I SACs from the $\mathrm{R}_{\mathrm{f}} 0.62$ band showed the presence of unsaturated carbon bonds $=\mathrm{CH}(\delta$ 5.39), saturated carbon bonds $-\mathrm{CH}\left(\begin{array}{lll}\delta & 0.4 & -2,5\end{array}\right)$ and amide bonds $(\delta 8.60)$.A structure consistent with the observed data and a $44 \mathrm{Da}$ repeated was, therefore, indeed $\left[-\left(\mathrm{CH}_{2}-\mathrm{CHOH}\right)-\right]_{\mathrm{n}}$. Alternatively, the $44 \mathrm{Da}$ repeating unit could result from acetylation $\left(\mathrm{CH}_{3}-\mathrm{CO}-, 43 \mathrm{Da}\right)$ of a carbon double bound, which would be expected to also result in the addition of a hydrogen atom to one of the other carbon atom of the double band, resulting in an increase in mass of $44 \mathrm{Da}$.

Two possible structures for the $[\mathrm{M}+\mathrm{H}]^{+}$ion of $\mathrm{m} / \mathrm{z} 502$, based on the combined analytical data discussed above, were:

1) $\mathrm{CH}_{3}-\left(\mathrm{CH}_{2}\right)_{14}-\left(\mathrm{CH}=\mathrm{CH}-\mathrm{CH}_{2}-\mathrm{CH}_{2}\right)_{3}-\mathrm{CH}=\mathrm{CH}-$ $\mathrm{CH}_{2}-\mathrm{CHOH}-\mathrm{CH}_{2}-\mathrm{CONH}_{2}$

2) $\mathrm{CH}_{3}-\left(\mathrm{CH}_{2}\right)_{7}-\mathrm{CH}=\mathrm{CH}-\left(\mathrm{CH}_{2}\right)_{2}-\mathrm{CH}=\mathrm{CH}-\left(\mathrm{CH}_{2}-\right.$ $\mathrm{CHOH})_{6}-\mathrm{CONH}_{2}$

ESI(+)-MS analysis of the TLC Type II band with $\mathrm{R}_{\mathrm{f}} 0.62$ produced a similar spectrum as that from the Type I band with $\mathrm{R}_{\mathrm{f}} 0.62$. Figure 4 shows the spectrum of the Type II SAC's from the TLC band with Rf 0.52. Again, a homologous mixture of 10 oligomers with a $\mathrm{m} / \mathrm{z}$ separation of 44 units was observed. However, the SACs from the $\mathrm{R}_{\mathrm{f}} 0.52$ band showed relevant changes in relative abundances with, for instance, more abundant ions of $\mathrm{m} / \mathrm{z} 546$ and $590 .{ }^{1} \mathrm{H}$ NMR analysis of this sample $\left(\mathrm{R}_{\mathrm{f}} 0.52\right)$ showed similar characteristics as that obtained in the spectra of band with $R_{f} 0.62$, suggesting the same basic structure.

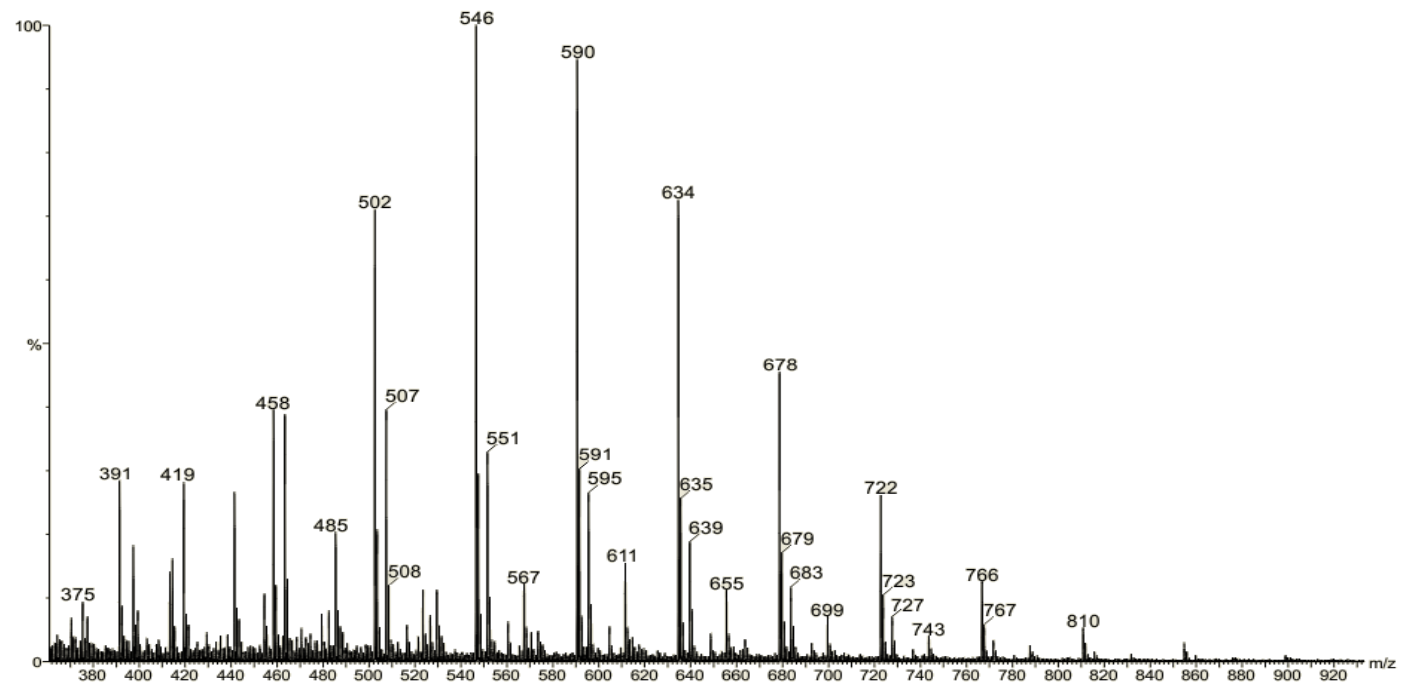

Figure 4 - ESI(+)-MS spectrum for the sample of $\mathrm{R}_{\mathrm{f}} 0.52$ from the extract Type II produced by Gordonia amicalis.

The crude extracts of the Type I and Type II SACs did not present antimicrobial activity at any of the concentrations assayed. The absence of antimicrobial activity is desirable for in-situ bioremediation to avoid the disruption of indigenous microbial communities that typically provide most of the biodegradation activity in contaminated sites.

In the genus Gordonia, the most extensively studied species for the production of SACs is G. amarae (Iwahori et al. 2001; Pagilla et al. 2002; Dogan et al. 2006). Franzettiet al. (2008) reported 
the production of at least two types of SACs byG. amicalis; however, structural characterization of these compounds was not performed. The present study showed that, depending on the isolation technique used, the G. amicalis used in this study yielded two types of SACs (Type I and II) with different activities, one which reduced the surface tension of water and produced $\mathrm{O} / \mathrm{W}$ emulsions (Type I) and one that primarily produced $\mathrm{W} / \mathrm{O}$ emulsions (Type II). The analysis by ESI(+)-MS, FT-IR and ${ }^{1} \mathrm{H}$ NMR indicated that the structure of the Type I and II SAC's were very similar. Both the preparations contained a homologous series of oligomers, differing by a structural repeating unit of $44 \mathrm{Da}$. The data indicated that the compounds contained $\mathrm{C}, \mathrm{N}$ and $\mathrm{O}$, and carbonyl, hydroxyl and amide bonds. The spectroscopic and spectrometric data of these compounds did not to match with other known biosurfactants and could represent a novel class of these interesting compounds. To elucidate further the structure of the identified SACs, the results showed that modified sugars and amino acids were possibly attached via the amide group. Lipids containing amide linkages to polar head groups are common in the cell membranes and lipopolysaccharides of Gram-negative bacteria in the form of ornithine-containing lipids and lipid A. They are present in the biosurfactant emulsion produced by Acinetobacter calcoaceticus RAG1(Gautam et al. 2006). Ornithine lipids with amide linkages have also been found in Mycobacterium (Lanéelle et al. 1990).

\section{CONCLUSIONS}

The specific activity of the crude SAC preparations was similar to the commercial surfactants tested in this study in terms of emulsification activity. It was likely that the superficial activity could be significantly increased with further purification. The ability to produce two different types of SAC activities by $G$. amicalis could be advantageous in applications in the chemical, cosmetic, food, biomedical applications and bioremediation industries.

\section{ACKNOWLEDGMENTS}

This work was supported by FAPESP (00/05092-0 and 98/11906-9).

\section{REFERENCES}

Arenskötter M, Broker D, Steinbuchel A. Biology of the metabolically diverse genus Gordonia. Appl Environ Microbiol. 2004; 70: 3195-3204.

Banat IM, Makkar RS, Cameotra SS. Potential commercial applications of microbial surfactants. Appl Microbiol Biotechnol. 2000; 53: 495-508.

Brown MJ. Biosurfactants for cosmetic applications. Int J Cosmet Sci. 1991; 3: 61-64.

Cole JR, Chai B, Farris RJ, Wang Q, Kulam-SyedMohideen AS, McGarrell D, et al. The ribosomal database project (RDP-II): introducing myRDP space and quality controlled public data. Nucleic Acids Res. 2007; 35: D169-D172.

Cole JR, Wang Q, Cardenas E, Fish J, Chai B, Farris RJ, et al. The Ribosomal Database Project: improved alignments and new tools for rRNA analysis. Nucleic Acids Res. 2009; 37: D141-D145.

de Araújo MEMB, Campos PRB, Noso TM, Alberici RM, Cunha IBS, Simas RC, et al. Response surface modeling of the production of structured lipids from soybean oil using Rhizomucor miehei lipase. Food Chem. 2011; 127: 28-33.

Dogan I, Pagilla KR, Webster DA, Stark BC. Expression of Vitreoscilla hemoglobin in Gordonia amarae enhances biosurfactant production. J Ind Microbiol Biotechnol. 2006; 33: 693-700.

Franzetti A, Bestetti G, Caredda P, La Colla P, Tamburini E. Surface-active compounds and their role in the access to hydrocarbons in Gordonia strains. FEMS Microbiol Ecol. 2008; 63: 238-248.

Gautam KK, Tyagi VK. Microbial surfactants: A review. J Olea Sci. 2006; 55: 155-166.

Iwahori K, Tokutomi T, Miyata N, Fujita M. Formation of stable foam by the cells and culture supernatant of Gordonia (Nocardia) amarae. J Biosci Bioeng. 2001; 92: 77-79.

Jacobucci DFC, Oriani MRG, Durrant LR. Reducing COD level on oily effluent by utilizing biosurfactantproducing bacteria. Braz Arch Biol Technol. 2009; 52:1037-1042.

Jacobucci DFC, Vasconcelos CK, Matsuura ABJ, Falconi FA, Durrant LR. Degradation of diesel oil by biosurfactant-producing bacterial strains. AEHS Contaminated Soil, Sediment and Water. 2001; 8: 3134.

Jacques RJS, Santos EC, Haddad R, Catharino RR, Eberlin MN, Bento FM, Camargo FAD. Mass spectrometry analysis of surface tension reducing substances produced by a path-degrading Pseudomonas citronellolis strain. Braz J Microbiol. 2007; 39: 352-353.

Lanéelle MA, Promé D, Lanéelle G,Promé JC. Ornithine lipid of Mycobacterium tuberculosis: its distribution in some slow- and fast-growing mycobacteria. J Gen Microbiol. 1990; 136: 773-778. 
Navon-Venezia S, Zosim Z, Gottlieb A, Legmann R, Carmeli S, Ron EZ, Rosenberg E. Alasan, a new bioemulsifier from Acinetobacter radioresistens. Appl Environ Microbiol. 1995; 61: 3240-3244.

Nitschke M, Costa SGVAO, Haddad R, Gonçalves LAG, Eberlin MN, Contiero J. Oil Wastes as Unconventional Substrates for Rhamnolipid Biosurfactant Production by Pseudomonas aeruginosa LBI. Biotechnol Prog. 2005; 21: 15621566.

Nitschke M, Haddad R, Costa GN, Gilioli R, Meurer EC, Gatti MSV, Eberlin MN, Höehr NF, Pastore GM. Structural Characterization and Biological Properties of a Lipopeptide Surfactant Produced by Bacillus subtilis on Cassava Wastewater Medium. Food Sci Biotechnol. 2004; 13: 591-596.
Pagilla KR, Sood A, Kim H. Gordonia (Nocardia) amarae foaming due to biosurfactant production. Water Sci Technol. 2002; 46: 519-24.

Rapp P, Backhaus S. Formation of extracellular lipases by filamentous fungi, yeast and bacteria. Enzyme Microb Technol. 1992; 14: 938-943.

Rocha C, San-Blas F, San-Blas GE, Vierma L. Biosurfactant production by two isolates of Pseudomonas aeruginosa. World J Microbiol Biotechnol. 1992; 8: 125-128.

Singh A, Van Hamme JD, Ward OP. Surfactants in microbiology and biotechnology: Part 2 - Application aspects. Biotechnol Adv. 2007; 25: 99-121.

Stanghellini ME, Miller RM. Biosurfactants - Their identity and potential efficacy in the biological control of zoosporic plant pathogens. Plant Dis. 1997; 81: 4-12. 